\title{
The Impact of the Epidemic on Employment
}

\author{
Nan Nan (Nancy) $)^{1, *}$
}

\author{
${ }^{1}$ Boston University, Boston, 02215, USA \\ *Corresponding author. Email: nan00006@bu.edu
}

\begin{abstract}
From 2019, COVID-19 has been sweeping the world at an extremely rapid pace. The disease is caused by the severe acute respiratory syndrome coronavirus type 2 , which is highly contagious and transmitted in a variety of ways, such as saliva, sweat, and droplets. And the number of deaths and infections around the world reached a peak. Therefore, to effectively control the spread of COVID-19, countries decided to adopt mandatory quarantine measures, that is, isolation at home, not going out.

The move proved effective in controlling the COVID-19 but it also created other problems. With people isolated from their homes, many companies are losing money and having to lay off workers to control costs. In this case, the amount of unemployment in each country has also reached a certain height. Many industries have been hit hard. At this time, with the control of COVID-19 on the agenda, the problem of unemployment has become one of the most important problems to be solved.

In view of this situation, the United States and China, the two major representative countries of developed and developing countries, bear the brunt of this situation, the two countries have taken corresponding measures considering their national conditions. China is using quarantine measures; the US is mainly using financial support as a strategy. As it stands, the measures taken in both countries are helping to contain COVID-19. Unemployment is also improving step by step.
\end{abstract}

Keywords: COVID-19, Measures, China, United States, policies

\section{INTRODUCTION}

So far, the epidemic has lasted more than a full year. The epidemic has also brought many problems. For example, people's health was severely hit, and families have pressure to quarantine for safety, resulting in a sudden increase in unemployment. As a result, China, and the United States, represented by two countries, have taken quarantine measures and financial support measures, respectively, to further control the outbreak. At the same time, it also sets an example for people in other countries.

To better analyze how to tackle unemployment, it is necessary first to understand how the epidemic has affected unemployment in different countries. Secondly, what policies China and the United States have adopted in this regard, and what impact they have had. It is also essential to know how other countries treat foreigners staying in their countries because of the pandemic. Finally, based on the current information, that will put up relevant suggestions and improvement space

COVID-19 causes unemployment problems in different countries

Because of the COVID-19 outbreak, people had to be forcibly quarantined at home, which caused many problems in their lives. One of the most obvious problems is the mass unemployment caused by the epidemic. According to the survey, $46 \%$ of U.S. households reported facing severe financial problems during the coronavirus outbreak [1]. At the same time, some serious problems of varying degrees were reported in many areas, including households struggling to make ends meet, problems paying credit card bills and other debts, and paying medical bills [1]. 


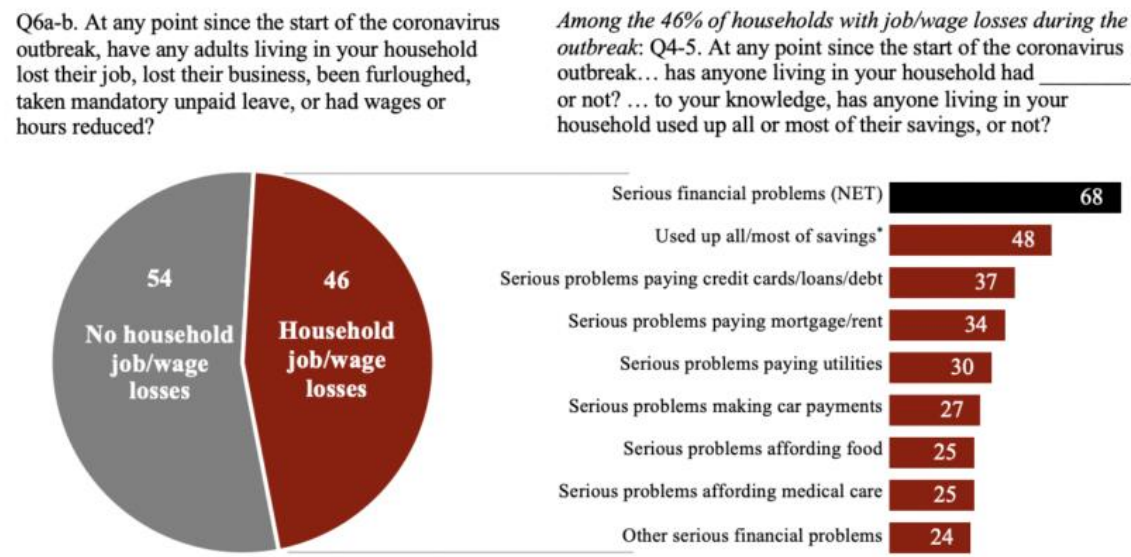

NPR/Robert Wood Johnson Foundation/Harvard T.H. Chan School of Public Health, The Impact of Coronavirus on Households Across America, $7 / 1 / / 20-8 / 3 / 20$. N=3,454 U.S. adults ages $18+$. Categories ranked by highest $\%$ among respondents. Serious financial problems is a composite measure of "yes" responses to Q4a-g and Q5. *An additional 11\% volunteered they didn't have any household savings prior to the coronavirus outbreak.

Figure 1 Serious Financial Problems Among U.S. Households with Job/Wage Losses During the Coronavirus Outbreak (in Percent) [1]

Sixty-eight percent are facing serious financial problems, while 48 percent are running out of savings and living beyond their means. Next, there are different people facing various types of financial problems.

As for China, which was the first country to report COVID-19 infection, the city closures are much stricter than in other countries. Furthermore, due to the unique of socioeconomic nature of China, farmers have been hardest hit [2]. As a result of the epidemic, most farmers were faced with a shrinking income, unemployment, and unstable life [2].

For Japan, maintaining a healthy 6 feet distance from others is a challenge. Because Japan is an island country with limited places and a high population density, especially in big cities like Tokyo, it can be difficult for people to maintain a healthy distance, leading to increased transmission [3].

Moreover, in some European countries, where people are not used to having their freedom of access restricted, many even think such rules might be a comfort rather than a help. In this case, people in Europe rarely comply with the mandatory quarantine order, making it difficult to control the outbreak in the early stages [3].

Many other countries were hit hard by the epidemic, but it is worth learning from the different policies that were put forward as people have recovered. Both developed and developing countries have their solutions.

\section{MEASURES TAKEN BY CHINA AND THE USA IN RESPONSE TO THE EPIDEMIC}

In response to the epidemic, each country put forward solutions that are relatively in line with its national conditions. Here, China and the United State as the two representatives of developing and developed countries will be analyzed to see what solutions they made to the epidemic.

\subsection{Measures taken by the United States in response to the epidemic}

In addition to essential protection and isolation measures, the United States has adopted different levels of financial assistance in three major phases: The first phase, which began on March 6, 2020, was the Supplementary Appropriations Act for Coronavirus Preparedness Response. $\$ 8.3$ billion in aid has provided financial support to contain the epidemic [4]. This was followed by the second phase, which began on March 18, 2020, with the Family First Coronavirus Response Act [4]. The American government has provided \$105 billion in aid, including paid sick leave, unemployment, and food aid. The final phase was the Coronavirus Assistance, Relief, and Economic Security Act, which began on March 27, 2020 [4]. The main objective is to provide financial stimulus to individuals and businesses by providing funds, which is the most prominent package for COVID-19 to date [4].

They were enacted simultaneously, but they were all very aggressive, and their primary purpose was basically to help the economy recover, provide relief to the 
unemployed, and give businesses more opportunity by providing government subsidy money.

\subsection{Measures taken by China in response to the epidemic}

At the beginning of the outbreak, China immediately blocked the seafood market in Wuhan and the entire city. Across China, the state set up thousands of health and quarantine stations in service areas and passenger entrances of railway stations [5]. Later, to further contain the outbreak, the government's search was expanded to include inspecting people in workplaces, shops, and on the streets. In addition, the government has adopted a more aggressive approach to health screening, sending officials to residents' homes and forcing patients to be isolated [5].

And China faces enormous challenges. The population is so dense that medical equipment cannot keep up. Therefore, China began to build new hospitals in Wuhan when the hospitals were about to be overcrowded [5]. It can be seen that China is trying its best to solve the problem of resource shortage caused by overpopulation.

In addition, the COVID-19 outbreak has severely disrupted the Chinese economy, with transport restrictions and restrictions disrupting the supply chain of enterprises and personnel isolation, further slowing business activities [6]. To alleviate this problem, the government has issued many targeted policies to support the survival and development of these enterprises during the epidemic [6]. Due to the financing cost of enterprises has decreased, during the epidemic period, many banks lowered the threshold of enterprise loans, increased the loan line which could help the business borrow more money to turn around, and lowered the loan interest rate [6]. Businesses severely affected by the epidemic can claim several tax breaks [6]. At the same time, the government also arranges special funds to provide subsidies to the industries most affected by the disease, such as aviation and transportation [6]. Employees returning from other places have also received strong support from the government, such as chartered flights and bus subsidies [6].

As the first country to detect the outbreak, China's response was really rapid. Isolation and treatment were provided immediately, not only at the site of the epidemic. It is also an excellent example for other clueless countries.

\subsection{Similarities and differences}

It is clear that most of the measures taken in the United States are economical. To ensure people's lives, economic assistance subsidies were carried out. On the other hand, China is more concerned with social stability, and most of the measures are to quarantine yourself in your home. The difference may be that the United States is a capitalist country, while China is a socialist country. The kind of countries are different. Many different measures will be taken in terms of management.

Although the United States is a developed country and China is a developing country, there are similarities in the measures. Both countries have recognized that unemployment is one of the epidemic's most serious issues, thus they have implemented subsidies for individuals and businesses. Contributions to individuals and businesses are hoped to help the economy gradually recover.

\section{THE POLICIES OF CHINA AND THE UNITED STATES TO HELP FOREIGNERS}

\subsection{U.S. policy for COVID on the treatment of foreigners living in the United States}

The COVID-19 pandemic has profoundly affected the talent of foreigners to travel to the United States in any capacity [7]. During the outbreak, the United States announced a moratorium on the entry of certain immigrants beginning April 24, 2020, and lasting at least until December 31, 2020, with the stated purpose of preserving employment opportunities for U.S. citizens affected by the economic impact of the pandemic. On June 24, the ban was expanded to include specific non-immigrant visas based on employment [7]. The government introduced the measure to minimize the impact on local people. In addition, many non-citizens, such as students studying abroad, were considered ineligible for emergency grants and had few options for financial assistance during the pandemic [7].

Although the United States has many restrictions for non-citizens, it also offers nucleic acid testing and other programs for non-citizens, and when a vaccine is developed, they can receive the vaccine for free.

\subsection{China's policy for COVID towards foreigners living in China}

China has also imposed travel restrictions on foreign travelers because of the outbreak. But after a vaccine was developed, China said it was willing to accept American travelers vaccinated with the American-made vaccine. Meanwhile, with the gradual improvement of the epidemic, China allows foreigners with valid residence permits to enter the country [8]. Crucially, China has also begun to restore air routes and gradually reconnect with the rest of the world.

Foreigners in China can also receive nucleic acid tests and vaccinations. In addition, some people from 
certain countries can enter China quickly without nucleic acid testing as long as they show proof [8].

Both China and the US have provided necessary guarantees for nucleic acid testing and vaccination of non-citizens. In China, the outbreak took a turn for the better with the birth of a vaccine. Therefore, people who have received vaccines and nucleic acid tests can leave and enter other countries, or they can choose to stay in China. For the United States, if the vaccine administered in China is officially approved, the country can enter and leave the United States. It is also a preparation for international students to go back to class.

Overall, a significant increase in vaccination rates in China and the United States, and perhaps in other countries, could help the economy recover faster so that people can get back to work and avoid further spread. In this case, vaccines can help alleviate the problem of unemployment.

\section{CONCLUSION}

COVID-19 isolated the world for a long time and hit the economies of all countries to varying degrees. On the other hand, the arrival of COVID-19 could be both a problem and an opportunity.

Because of COVID-19, the economic balance of all industries has been disrupted. And because COVID-19 was a force majeure disaster, the market could not adjust itself for a while, resulting in substantial economic losses. Perhaps the most serious of these problems is unemployment. To control the epidemic, people must be forced to quarantine at home, some enterprises to control costs, and lay off staff to ensure revenue. In addition, due to travel restrictions in all countries, some people are trapped in other countries without proper protection, which is a huge blow both physically and mentally. But the good news is that the response has been swift. Most developed countries, led by the United States, have adopted government subsidies to intervene in the economy to bring the economy back to a state of balance. Developing countries, led by China, pay more attention to protecting people's livelihood, which is in line with their national conditions, and thus the epidemic has been well controlled.

Besides, the economic losses caused by the epidemic cannot be remedied overnight. There are many challenges ahead for China. Due to the new crown, China's trade will be significantly impacted and may face problems such as capital shortage, declining orders, and increased supply chain risks [9]. To improve the situation, China could gradually resume air trade by first restoring the routes of major air routes, and then depending on the condition of the epidemic, deciding whether to renew the sea trade. All this is done on the premise of ensuring safety.
Overall, the challenge and opportunity of the epidemic depend on the initiative of the country. Whether COVID-19 is an opportunity or a challenge depends on whether the government can grasp the trend of the economic situation, strive to develop sustainable development of green finance so that the national economy as soon as possible to recover.

\section{ACKNOWLEDGMENTS}

Thank you for your careful instruction and detailed explanation of the framework and content of the paper. Thank you very much, teachers.

\section{REFERENCES}

[1] Poll: $46 \%$ of U.S. households report facing serious financial problems during the coronavirus outbreak. News. (2020, September 23). https://www.hsph.harvard.edu/news/press-releases/ poll-46-of-u-s-households-report-facing-serious-fin ancial-problems-during-the-coronavirus-outbreak/.

[2] Tang, S., \&amp; Li, X. (2021, January 6). Responding to the pandemic as a family unit: social impacts of COVID-19 on rural migrants in China and their coping strategies. Nature News. https://www.nature.com/articles/s41599-020-00686 -6 .

[3] Maria , C. (2020). What is the global impact of the new coronavirus pandemic? Medical News Today. https://www.medicalnewstoday.com/articles/covid19-global-impact-how-the-coronavirus-is-affecting -the-world\#Too-little,-too-late.

[4] KPMG. (2020, April 14). United States of America. KPMG.

https://home.kpmg/xx/en/home/insights/2020/04/un ited-states-of-america-government-and-institutionmeasures-in-response-to-covid.html.

[5] Liu, W., Yue, X.-G., \&amp; Tchounwou, P. B. (2020, March 30). Response to the COVID-19 Epidemic: The Chinese Experience and Implications for Other Countries. International journal of environmental research and public health.

https://www.ncbi.nlm.nih.gov/pmc/articles/PMC71 77503/.

[6] AlTakarli, N. S. (2020, May 19). China's Response to the COVID-19 Outbreak: A Model for Epidemic Preparedness and Management. Dubai Medical Journal. https://www.karger.com/Article/FullText/508448.

[7] Jorge, L., Aaron, R.-M., \&amp; Walter, E. (2021, April 28). The Impact of COVID-19 on Noncitizens and Across the U.S. Immigration 
System. American Immigration Council. https://www.americanimmigrationcouncil.org/resea rch/impact-covid-19-us-immigration-system.

[8] Zoey, Z. (2021, April 23). China's Travel Restrictions due to COVID-19: An Explainer (Updated). China Briefing News. https://www.china-briefing.com/news/chinas-travel -restrictions-due-to-covid-19-an-explainer/.
[9] Reuters, S. (2020, May 18). China's trade faces 'unprecedented' challenges amid pandemic: commerce minister. Reuters. https://www.reuters.com/article/us-china-economytrade/chinas-trade-faces-unprecedented-challengesamid-pandemic-commerce-minister-idUSKBN22U 07U. 